\title{
Genetic differentiation and population structure of Anopheles funestus from Uganda and the southern African countries of Malawi, Mozambique, Zambia and Zimbabwe
}

\author{
Martha A. Kaddumukasa ${ }^{1 *}$, Jane Wright ${ }^{2}$, Mbanga Muleba ${ }^{3}$, Jenny C. Stevenson ${ }^{3,4}$, Douglas E. Norris ${ }^{4}$
} and Maureen Coetzee ${ }^{1,5}$

\begin{abstract}
Background: Anopheles funestus (s.s.) is a primary vector of the malaria parasite Plasmodium falciparum in Africa, a human pathogen that causes almost half a million deaths each year. The population structure of An. funestus was examined in samples from Uganda and the southern African countries of Malawi, Mozambique, Zambia and Zimbabwe.

Methods: Twelve microsatellites were used to estimate the genetic diversity and differentiation of An. funestus from 13 representative locations across five countries. These were comprised of four sites from Uganda, three from Malawi and two each from Mozambique, Zambia and Zimbabwe.

Results: All loci were highly polymorphic across the populations with high allelic richness and heterozygosity. A high genetic diversity was observed with 2-19 alleles per locus and an average number of seven alleles. Overall, expected heterozygosity $\left(\mathrm{H}_{\mathrm{e}}\right)$ ranged from 0.65 to 0.79 . When samples were pooled three of the 12 microsatellite loci showed Hardy-Weinberg equilibrium. Unsupervised Bayesian clustering analysis of microsatellite data revealed two clusters with An. funestus samples from Mozambique, Uganda and Zambia falling into one group and Malawi and Zimbabwe into another. The overall genetic differentiation between the populations was moderate $\left(F_{S T}=0.116\right)$. Pairwise differentiation between the pairs was low but significant. A weak but significant correlation was established between genetic and geographical distance for most populations.

Conclusions: High genetic diversity revealed by the loci with low to moderate differentiation, identified two clusters among the An. funestus populations. Further research on the population dynamics of An. funestus in east and southern Africa is essential to understand the implications of this structuring and what effect it may have on the efficient implementation of mosquito vector control strategies.
\end{abstract}

Keywords: Anopheles funestus, Population differentiation, Malaria, Microsatellites, East Africa, Southern Africa

*Correspondence: mkaddumukasa@gmail.com

${ }^{1}$ Wits Research Institute for Malaria, School of Pathology, Faculty of Health Sciences, University of the Witwatersrand, Johannesburg, South Africa

Full list of author information is available at the end of the article

\begin{abstract}
Background
Anopheles funestus (sensu stricto) is present throughout most of sub-Saharan Africa and is one of the four most important vectors of human malaria parasites [1-3]. In parts of east and southern Africa, its importance as a vector exceeds that of members of the An. gambiae complex
\end{abstract}

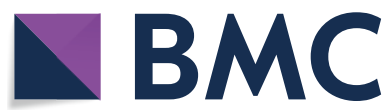

c The Author(s) 2020. This article is licensed under a Creative Commons Attribution 4.0 International License, which permits use, sharing, adaptation, distribution and reproduction in any medium or format, as long as you give appropriate credit to the original author(s) and the source, provide a link to the Creative Commons licence, and indicate if changes were made. The images or other third party material in this article are included in the article's Creative Commons licence, unless indicated otherwise in a credit line to the material. If material is not included in the article's Creative Commons licence and your intended use is not permitted by statutory regulation or exceeds the permitted use, you will need to obtain permission directly from the copyright holder. To view a copy of this licence, visit http://creativeco mmons.org/licenses/by/4.0/. The Creative Commons Public Domain Dedication waiver (http://creativecommons.org/publicdomain/ zero/1.0/) applies to the data made available in this article, unless otherwise stated in a credit line to the data. 
$[1,4]$. The traditional methods of vector control, insecticide-treated bednets and indoor residual house spraying, have been very effective in controlling An. funestus due to its strong association with humans and human habitations $[1,2]$. However, the development of insecticide resistance across the region $[5,6]$ has seen vector control programs compromised in some places [7-9]. This has also played an important role in the slow-down of the gains made in malaria control over the past 10 years in Africa [10, 11]. To achieve the goals of malaria elimination and eradication, not only are new products and interventions needed, but monitoring the effectiveness of all vector control interventions is crucial.

Mosquito vector surveillance covers the monitoring of all aspects of mosquito biology, from geographical distribution to the more complex genetic diversity within and between populations. Studies of population genetics provide insight into gene flow between mosquito populations and through that, the likelihood of the spread of genes (e.g. those conferring insecticide resistance) across geographical regions. In east and southern Africa, studies focused on the population structure of An. funestus have been carried out in Uganda [12-14], Malawi [12, 15-17], Kenya [18], Tanzania [19], Mozambique [12, 16, 17] and Zambia [16]. These and other studies have revealed various levels of differentiation over the African continent, from no or very low structure to high population structure of An. funestus [12-19].

Understanding the gene flow dynamics of populations of malaria vector mosquitoes is important for strategic planning of vector control interventions. In this study, the population structure of An. funestus was examined using specimens from one country in east Africa (Uganda) and four countries in southern Africa (Malawi, Mozambique, Zambia and Zimbabwe). Twelve microsatellite markers distributed across all five chromosome arms were used to address the questions: (i) Is there any evidence for population genetic subdivision within this collection of $A n$. funestus? and (ii) What is the maximum amount of differentiation observed within each selected site? Population structure analysis quantifies the amount of genetic exchange that occurs between sample sets and provides insight on how these underlying genetic components may be used to address biological phenomena such as insecticide resistance, parasite transmission and dispersal of the mosquito.

\section{Methods}

\section{Mosquito collection study sites}

Preserved mosquito samples from selected sites (Table 1) in five African countries (Malawi, Mozambique, Uganda, Zambia and Zimbabwe) (Fig. 1) were used. From Malawi, sample collections were from three sites; Karonga, Majete and Likoma Island. Karonga is found in the far north of
Malawi, Majete is an area near Majete Wildlife Reserve in the south-west of Malawi, and Likoma is an island in the north eastern corner of Lake Malawi close to Mozambique. In Malawi, Karonga has two seasons, a dry season from May to mid-November and a wet season from midNovember to April, temperature varies between 16.11$33.3^{\circ} \mathrm{C}$ and humidity varies between $54-79 \%$. In Likoma, the wet season starts from November to April and the rest of the year from May to October is almost dry. Temperatures vary between $22.4-31.4{ }^{\circ} \mathrm{C}$ and humidity varies between 43.7-83.6\%. In Majete there are two distinct seasons, the dry season from May to September and the wet season from November to April. Temperature varies between $22-34{ }^{\circ} \mathrm{C}$ and the average humidity is $71 \%$.

In Mozambique, samples were collected from Maciana and Matola, near Maputo in southern Mozambique. Matola is the largest suburb of Maputo and lies on the coastal plain north of Espirito Santo estuary. In Matola, found $42 \mathrm{~m}$ above sea level, the climate is characterized by a warm and wet season from December to March, and a dry and cold season from June to August. Precipitation averages $1050 \mathrm{~mm}$ (41 inches) per year, with abundant rainfall from December to March, and rare rains from May to October. Temperature varies between $15-34{ }^{\circ} \mathrm{C}$ and relative humidity ranges between $28-89 \%$. Maciana, at $68 \mathrm{~m}$ above sea level is characterized by a warm and wet season from November to April, and a dry and cold season from May to October. Precipitation averages $815 \mathrm{~mm}$ (32 inches) per year, most of which falls from November to March. The rainiest month is January $(170 \mathrm{~mm})$. Temperature varies between $11-34{ }^{\circ} \mathrm{C}$ and relative humidity ranges between $59-67 \%$.

Uganda experiences a warm tropical climate with heavy rains in March-May and September-November for the South. In northern Uganda, the wet season extends from April to November with peaks in April and August. Samples were obtained from Agule, Apac, Lira and Kamuli districts in North and central Uganda. Agule and Apac were originally one district so do not have much variation in climate characteristics. Agule lies $1034 \mathrm{~m}$ above sea level. Temperature varies between $20-34{ }^{\circ} \mathrm{C}$ and relative humidity varies between 28-88\%. Apac lies on $1040 \mathrm{~m}$ above sea level with a tropical climate, over the course of the year, the temperature varies between $18-35{ }^{\circ} \mathrm{C}$. Temperatures are highest in February, with an average of around $25.1{ }^{\circ} \mathrm{C}$, whilst July is the coldest month of the year with an average of $22.1{ }^{\circ} \mathrm{C}$. Precipitation over this area, averages $1305 \mathrm{~mm}$. Humidity varies between $21 \%$ and $69 \%$. Lira lies at $1091 \mathrm{~m}$ above sea level and has an average temperature of $23.2{ }^{\circ} \mathrm{C}$ and a yearly average precipitation of $1376 \mathrm{~mm}$. The wet season runs from April to mid-November and with two dry seasons (December 
to February and June to August). February is the warmest month of the year with an average temperature of $33{ }^{\circ} \mathrm{C}$. July has the lowest average temperature, with an average of $21.6{ }^{\circ} \mathrm{C}$. Overall, the average humidity for Lira is $58 \%$. On the other hand, Kamuli lies $1185 \mathrm{~m}$ above sea level and temperature varies between 15.5$32{ }^{\circ} \mathrm{C}$. March is the warmest month of the year, with an average temperature of $22.7^{\circ} \mathrm{C}$, whilst July has the lowest average temperature of $20.7^{\circ} \mathrm{C}$. There is a great deal of rainfall in Kamuli, even in the driest month (January) with $63 \mathrm{~mm}$ of rainfall. April is the wettest with an average of $193 \mathrm{~mm}$. Average rainfall is $1325 \mathrm{~mm}$ over the year. Humidity varies between $62-95 \%$.

Zambian collections were from Nchelenge and Namwala. Namwala is located in the north-western corner of the southern province next to Kafue National Park. Zambia has a tropical climate, which experiences wet and dry periods. In Namwala, the wet season lasts from mid-November to March and the dry season from end of November to April. The cool season is from May to August with temperatures varying between $10-27^{\circ} \mathrm{C}$ and the dry season from September to November with temperatures around $26{ }^{\circ} \mathrm{C}$ to $37{ }^{\circ} \mathrm{C}$ and humidity between $19-75 \%$. Some days are particularly dry where humidity can be as low as $0 \%$. Nchelenge district is located near the Democratic Republic of Congo next to Lake Mweru. For Nchelenge, the wet season lasts from September to May and the dry season from end of May to September. The cool season is from December to April with temperatures varying between $15-27^{\circ} \mathrm{C}$. The hot season is from September to October with temperatures around $22{ }^{\circ} \mathrm{C}$ to $34{ }^{\circ} \mathrm{C}$ and humidity varying between $22-89 \%$. In Nchelenge, humidity can also reach a low of $0 \%$.

In Zimbabwe, samples were obtained from Honde and Mangwanda. Both sites are located within Mutasa district. In Zimbabwe, Honde, from late October to around the end of April, the weather is hot and humid. Temperatures rise up to $28{ }^{\circ} \mathrm{C}$ and is when most of the convectional rainfall is received. Average rainfall is $1150 \mathrm{~mm}$. From May to the beginning of July, the temperatures are very low, up to $2{ }^{\circ} \mathrm{C}$, whilst August is very windy. During September to October very hot temperatures are recorded, where the maximum temperature may average $30{ }^{\circ} \mathrm{C}$. Humidity varies between $11-45 \%$. In Mangwanda, the climate is warm and temperate. The summers have much more rainfall with an average of $809 \mathrm{~mm}$. From May to August the temperatures are very low, varying between $9-16{ }^{\circ} \mathrm{C}$, while August is very windy. From September to December, it is very hot and the temperatures range between $16-28{ }^{\circ} \mathrm{C}$. The average humidity is $73 \%$.

\section{Mosquito collection and identification}

Specimens were collected using indoor aspirations for all mosquitoes mainly in the living/sleeping area of the houses (huts), but for two sites human landing catches were carried out (Table 1). Anopheline mosquitoes were identified morphologically [2] and preserved individually

Table 1 Country and sampling sites, number of specimens collected, collection method, and malaria transmission intensity

\begin{tabular}{|c|c|c|c|c|c|c|c|c|}
\hline Country & Site & Coordinates $^{a}$ & $n$ & Clade I & Clade II & Method $^{b}$ & Collection date & Transmission intensity \\
\hline \multirow[t]{3}{*}{ Malawi } & Karonga & $-9.933,33.933$ & 13 & 13 & - & IAC & December 2007, 2010 & High (> 1 case per 1000 population) \\
\hline & Majete & $-15.785,34.008$ & 26 & 26 & - & IAC & May 2012 & High (> 1 case per 1000 population) \\
\hline & Likoma & $-12.067,34.733$ & 21 & 21 & - & IAC & May 2010 & High (> 1 case per 1000 population) \\
\hline \multirow[t]{2}{*}{ Mozambique } & Maciana & $-25.449,32.781$ & 34 & 28 & 6 & IAC & April 2011 & High (> 1 case per 1000 population) \\
\hline & Matola & $-25.962,32.459$ & 36 & 30 & 6 & IAC & October 2012 & High (> 1 case per 1000 population) \\
\hline \multirow[t]{4}{*}{ Uganda } & Agule & $1.667,33.817$ & 13 & 13 & - & $\mathrm{HLC}$ & April 2013 & High (> 1 case per 1000 population) \\
\hline & Apac & $1.983,32.533$ & 20 & 20 & - & IAC & August 2016 & High (> 1 case per 1000 population) \\
\hline & Lira & $2.235,32.909$ & 10 & 10 & - & $\mathrm{HLC}$ & April 2013 & High (> 1 case per 1000 population) \\
\hline & Kamuli & $0.947,33.120$ & 20 & 19 & 1 & IAC & August 2016 & High (> 1 case per 1000 population) \\
\hline \multirow[t]{2}{*}{ Zambia } & Nchelenge & $-9.345,28.734$ & 30 & 22 & 8 & IAC & April 2013, 2015 & High (> 1 case per 1000 population) \\
\hline & Namwala & $-15.750,26.450$ & 30 & 18 & 12 & IAC & January 2012 & Low (<1 case per 1000 population) \\
\hline \multirow[t]{2}{*}{ Zimbabwe } & Honde & $-18.497,32.853$ & 35 & 35 & - & IAC & February 2013 & $\begin{array}{l}\text { Seasonal and geographic variation in malaria } \\
\text { transmission }\end{array}$ \\
\hline & Mangwanda & $-18.570,31.526$ & 35 & 35 & - & IAC & March 2013, May 2014 & $\begin{array}{l}\text { Seasonal and geographic variation in malaria } \\
\text { transmission }\end{array}$ \\
\hline
\end{tabular}

\footnotetext{
${ }^{a}$ Latitude, longitude

${ }^{\mathrm{b}}$ Human landing and indoor aspiration collections were done in the living/sleeping areas of the huts IAC, Indoor aspiration catch, HLC, Human Landing Catch Note: Reference https://www.who.int/malaria/publications/country-profiles/profile_

Abbreviation: $\mathrm{n}$, number of specimens collected
} 


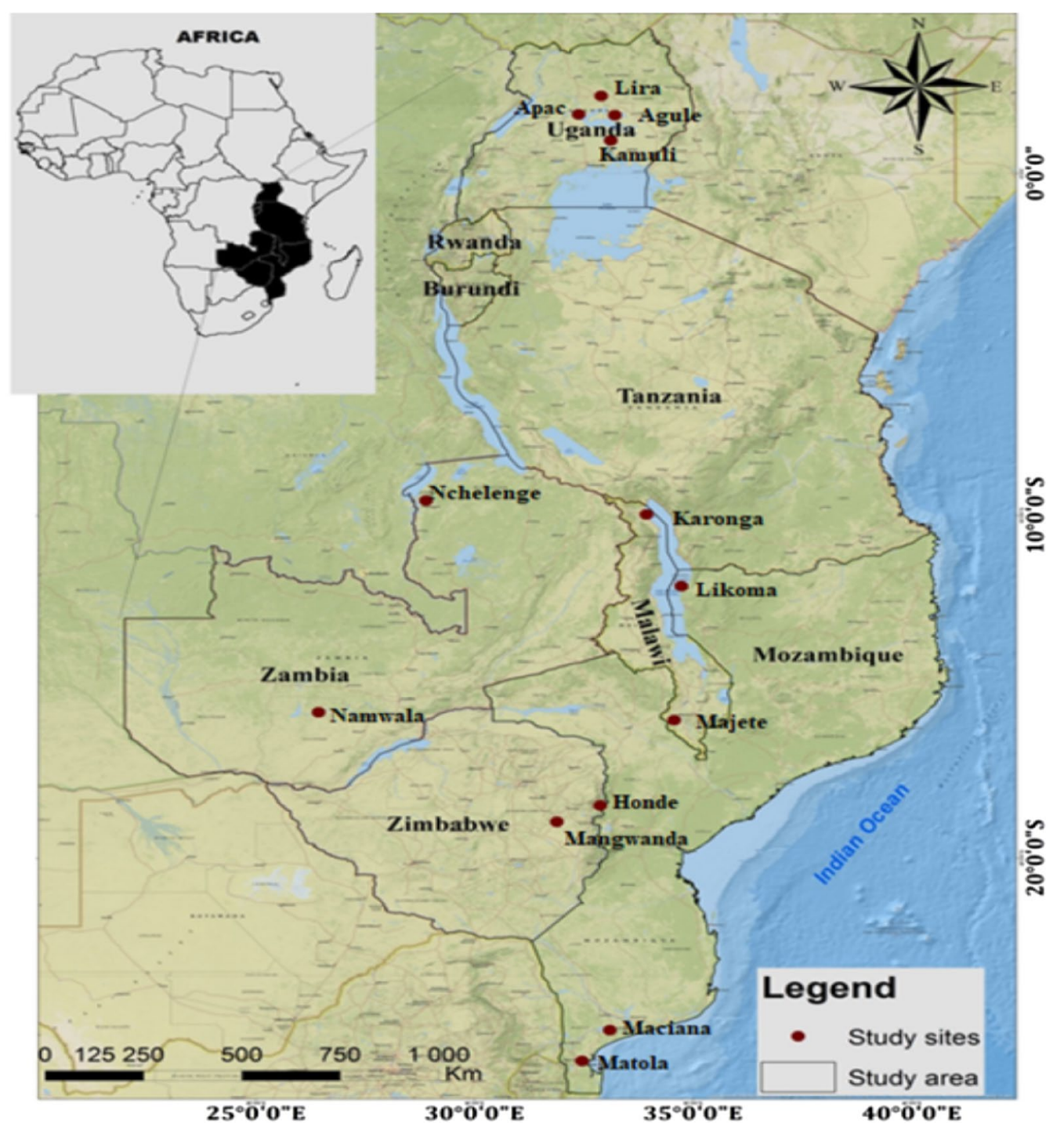

Fig. 1 Mosquito collection sites from five African countries

in $0.6 \mathrm{ml}$ microcentrifuge tubes with silica gel and stored at room temperature until processing. Molecular identification was carried out using the standard method of Koekemoer et al. [20] and the clade TaqMan assay of Choi et al. [21].

\section{DNA extraction and microsatellite genotyping}

Genomic DNA extractions were performed on the legs of the individual An. funestus mosquitoes using a DNA extraction kit prepGEM ${ }^{\circledR}$ Insect (Cat. No. PIN0050; ZyGEM, Hamilton, New Zealand) following the manufacturer's instructions. In short, a leg of an individual mosquito was homogenized with reagents, incubated for $15 \mathrm{~min}$ at $75^{\circ} \mathrm{C}$ and at $95^{\circ} \mathrm{C}$ for $5 \mathrm{~min}$. A $10 \mu \mathrm{l}$ elution of genomic DNA was obtained for each sample from the extraction.
Twelve microsatellite loci were selected from previously published An. funestus sequence data [22-25], based on their high polymorphism and no evidence for null alleles. These microsatellites were: FUNF and AFUB12 on chromosomal arm 3L; AFND19, AFND20 and AFND41 on 3R; AFUB10, AFUB11, FUNL and AFND23 located on 2L; AFUB3 and FUNO located on 2R; and FUNQ on X (Table 2). PCR amplification of the microsatellite loci was carried out individually in a $25 \mu \mathrm{l}$ reaction volume, using 5-10 ng of template DNA. The reaction mixture contained $2.5 \mu \mathrm{l}(1 \times \mathrm{PCR})$ buffer (Takara Bio Inc, Shiga, Japan), $1.5 \mathrm{mM} \mathrm{MgCl}$ (Takara Bio Inc), $0.2 \mathrm{mM}$ of each dNTP (Takara Bio Inc), $10 \mathrm{pmol}$ of each primer, $0.1 \mathrm{U}$ of Taq DNA polymerase (Takara Bio Inc). The forward primer was labelled at the $5^{\prime}$-end with either PET, HEX or 6-FAM 
Table 2 Primer sequences and characteristics of 12 polymorphic microsatellite loci

\begin{tabular}{|c|c|c|c|c|c|c|}
\hline Locus & $\begin{array}{l}\text { Chromosome } \\
\text { arm }\end{array}$ & Repeat motif & No. of alleles & Allele size & Primer sequence $\left(5^{\prime}-3^{\prime}\right)$ & Reference \\
\hline FunL F & \multirow[t]{2}{*}{$2 \mathrm{~L}$} & \multirow[t]{2}{*}{$(G T)_{8}$} & \multirow[t]{2}{*}{12} & \multirow[t]{2}{*}{$181-197$} & HEX-AACAGTGGAAGGCAAATTGC & \multirow[t]{2}{*}{ Cohuet et al. [22] } \\
\hline FunL R & & & & & GCACGGTTACCACTGCTCA & \\
\hline AFUB10 F & \multirow[t]{2}{*}{$2 \mathrm{~L}$} & \multirow[t]{2}{*}{$(\mathrm{GCT})_{3+2+4+5}$} & \multirow[t]{2}{*}{6} & \multirow[t]{2}{*}{$195-210$} & PET-TGTCCATGTACAACCGCAAC & \multirow[t]{2}{*}{ Sharakov et al. [23] } \\
\hline AFUB10 R & & & & & TTCTCCAGCATCATCAGCAC & \\
\hline AFUB11 F & \multirow[t]{2}{*}{$2 \mathrm{~L}$} & \multirow{2}{*}{$(\mathrm{CTG})_{3+5+2+2}$} & \multirow[t]{2}{*}{4} & \multirow[t]{2}{*}{ 188-191 } & PET-CAGTTTCTGCGTGGAGGAAT & \multirow[t]{2}{*}{ Sharakov et al. [23] } \\
\hline AFUB11 R & & & & & AGCAGCTGATGAGCCATCTC & \\
\hline AFND23 F & \multirow[t]{2}{*}{$2 \mathrm{~L}$} & \multirow[t]{2}{*}{$(\mathrm{GT})_{11}$} & \multirow[t]{2}{*}{11} & \multirow[t]{2}{*}{$133-157$} & 6-FAM-TTTGATCGACGGACTAGTGTGT & \multirow[t]{2}{*}{ Schemerhorn et al. [25] } \\
\hline AFND23 R & & & & & GGTTTGATGGGTGGAAAC & \\
\hline FunO F & \multirow[t]{2}{*}{$2 \mathrm{R}$} & \multirow[t]{2}{*}{$(C A)_{6} T(A C)_{4}$} & \multirow[t]{2}{*}{10} & \multirow[t]{2}{*}{$110-132$} & PETGCACACATTTCAGGCAGC & \multirow[t]{2}{*}{ Cohuet et al. [22] } \\
\hline FunO R & & & & & GCCCACATTCTGCACCTT & \\
\hline AFUB3 F & \multirow[t]{2}{*}{$2 \mathrm{R}$} & \multirow{2}{*}{$(\mathrm{CAG})_{2+3+2}$} & \multirow[t]{2}{*}{5} & \multirow[t]{2}{*}{$171-195$} & VIC-GGGAAGGATTCGACCTTAGC & \multirow[t]{2}{*}{ Sharakov et al. [23] } \\
\hline AFUB3 R & & & & & GCCGCCATTTAGTAGCAGTT & \\
\hline FunF F & \multirow[t]{2}{*}{$3 \mathrm{~L}$} & \multirow[t]{2}{*}{$(\mathrm{TG})_{9}$} & \multirow[t]{2}{*}{7} & $104-118$ & 6-FAM -GCCTTCAGTTTCGATTGGCG & Cohuet et al. [22] \\
\hline FunF R & & & & & AATAAGATGCGACCGTGGC & \\
\hline AFUB12 F & $3 \mathrm{~L}$ & $(\mathrm{AGG})_{7}(\mathrm{TG})_{4}$ & 3 & $152-158$ & VIC -TGGGGAACTGGTCGTTAGAG & Sharakov et al. [23] \\
\hline AFUB12 R & & & & & CTGGTGATGGGATTGAGGAT & \\
\hline AFND19 F & $3 R$ & $(\mathrm{AG})_{12}(\mathrm{TG})_{5}$ & 8 & $251-285$ & HEX -GCAAGCTGTACGCAGAGAG & Sharakov et al. [24] \\
\hline AFND19 R & & & & & ATCGATGGGAGTTATTATACGC & \\
\hline AFND20 F & $3 R$ & $(\mathrm{GAG})_{4+2+2+2}(\mathrm{TGG})_{3}$ & 2 & $239-242$ & VIC- CGGCGCAGGTTTAGTAGC & Sharakov et al. [24] \\
\hline AFND20 R & & & & & CCCTCGCTTTCCTCATAAAA & \\
\hline AFND41 F & $3 R$ & $(\mathrm{CA})_{3} \mathrm{TC}(\mathrm{CA})_{6}$ & 6 & $222-246$ & 6-FAM AGAACATATGGCAAATCGAC & Schemerhorn et al. [25] \\
\hline AFND41 R & & & & & GAAAGACTTGTCGGACGTG & \\
\hline FunQ F & $x$ & $(\mathrm{TG})_{9}$ & 7 & $84-98$ & HEX -GCAAACTGCTAGTAAATGTTTCC & Cohuet et al. [22] \\
\hline FunQ R & & & & & ACATTTCCACAATTTGCGC & \\
\hline
\end{tabular}

fluorescent markers to allow multiplex electrophoresis. Amplification was carried out with a $\mathrm{T} 100^{\mathrm{TM}}$ thermal cycler (Bio-Rad, Hercules, USA), under the following conditions: an initial denaturation step at $94{ }^{\circ} \mathrm{C}$ for $2 \mathrm{~min}$; 36 cycles of $30 \mathrm{~s}$ at $94{ }^{\circ} \mathrm{C}, 30 \mathrm{~s}$ at $54{ }^{\circ} \mathrm{C}, 30 \mathrm{sec}$ at $72{ }^{\circ} \mathrm{C}$; and a final elongation step of $10 \mathrm{~min}$ at $72{ }^{\circ} \mathrm{C}$. Fragment analysis was performed commercially at Macrogen (Seoul, South Korea) with an ABI PRISM 377 (Thermo Fisher Scientific, MA, USA). Alleles were sized relative to an internal size standard using Peak Scanner v1.0 (Applied Biosystems, Toulouse, France). Output files (".fsa) generated by the autosequencer were loaded into Peak Scanner ${ }^{\mathrm{TM}}$ software. Determination of fragment size was performed using default settings, with GS500LIZ specified as size standard and 'PP - Primers Present' in the 'Analysis Method' column. Peak information showing height, area and size were labelled and scored. The resulting fragment sizes were used for further analyses.

\section{Microsatellite diversity, differentiation and structure analysis}

Microsatellite allele and genotype frequencies were determined using Arlequin 3.5 [26] and FSTAT 2.9.3
[27]. These frequencies were then used to assess deviation from Hardy-Weinberg equilibrium at each locus, each population sample, and overall as indicated by the inbreeding coefficient $\left(\mathrm{F}_{\mathrm{IS}}\right)$. Linkage disequilibrium between pairs of microsatellite loci was assessed using FSTAT 2.9.3 [27]. The level of genetic differentiation between sampling groups was assessed using $\mathrm{F}_{\mathrm{ST}}$ [28]. Pairwise $\mathrm{F}_{\mathrm{ST}}$ between sampling groups and their significance was assessed using the randomization approach implemented in FSTAT 2.9.3 with Bonferroni-adjusted $P$-values.

The significance of genetic differentiation between populations based on allelic distribution across populations was examined using a Fisher exact test with FSTAT 2.9.3 [27]. The pairwise $\mathrm{F}_{\mathrm{ST}}$ was assessed by estimating Wright's F-statistics, calculated according to Weir \& Cockerham [28]. A locus by locus analysis of molecular variance (AMOVA) [29] was performed using Arlequin 3.5 to determine the relative contribution of within-sampling groups and between sampling group's genetic diversity to the overall genetic diversity. Finally, population structure was inferred using a Bayesian model-based clustering algorithm to assign individuals (probabilistically) 
to clusters without prior knowledge of population units and limits in STRUCTURE 2.3.4 [29, 30]. This model calculates the probabilities of each individual for each subgroup within which Hardy-Weinberg ( $\mathrm{H}-\mathrm{W})$ equilibrium and linkage equilibrium are minimized. Using the STRUCTURE program, the numbers of distinct genetic clusters in the data set $(\mathrm{K})$ are estimated from 1 to 10 by posterior $\log$ probability of data under $\mathrm{K}, \mathrm{Ln}[\operatorname{Pr}(\mathrm{X} \mid \mathrm{K})]$. Each run was carried out with 1,000,000 iterations after a 'burn-in' period of 100,000, using the admixture model and correlated allele frequencies. To check for convergence of the Markov Chain Monte Carlo (MCMC), 5 replicates for each value of $\mathrm{K}$ were checked for the consistency of results $[29,30]$. Based on allele diversity, individuals with unique alleles were grouped together into assumed populations (K) which is pre-determined. The $\mathrm{K}$ value with the maximum posterior probability $\mathrm{Pr}$ $(\mathrm{X} \mid \mathrm{K})$ value was retained and assumed to be the most probable number of clusters in that population. The estimated number of clusters $(K)$ is taken to be the value of $\mathrm{K}$ with the highest $\operatorname{Pr}(\mathrm{X} \mid \mathrm{K})$. All obtained files were run through Structure Harvester [31] followed by CLUMPP [32] and DISTRUCT [33]. The visual representations of the clusters were viewed in Ghostview, a graphical interface for Ghostscript (https://www.ghostscript.com). As an estimate of gene flow, the number of migrants per population per generation $\left(\mathrm{Nm} \approx\left(1-\mathrm{F}_{\mathrm{ST}}\right) / 4 \mathrm{~F}_{\mathrm{ST}}\right.$ was conducted [34]. The correlation between genetic and geographical distances was assessed by the regression of $\mathrm{F}_{\mathrm{ST}} /$ $\left(1-\mathrm{F}_{\mathrm{ST}}\right)$ on the logarithm $(\mathrm{ln})$ of geographical distance, in GenALEx 6.503 [35, 36].

\section{Principal coordinates analysis}

For the majority of the time, principal coordinates analysis (PCoA) uses Euclidean distance between two points that are being compared. To visualize the genetic relatedness among individuals, we performed PCoA after all the preliminary analyses using the GenALEx 6.503 [35, 36] program to explore the relationships between the $A n$. funestus samples. PCoA was conducted based on mosquito genotypes. The genotypes at each site were transformed with natural $\log (\ln (x+1))$. Then, the sites on the PCoA ordination map were marked as groups from the cluster analysis extracted from the collected sites. PCoA is an indirect gradient analysis method for seeking the strongest linear correlation structure among variables $[35,36]$ and it is a technique widely used for reducing the dimensions of multivariate problems. In the PCoA, eigenvalues, which explain a portion of the original total variance, were calculated. Each axis score using the eigenvector, which contains the coefficients of the linear equation for a given axis, was shown in an ordination [35, 36].

\section{Results}

\section{Mosquito identification}

A total of 323 An. funestus individuals were identified from the 13 localities. Both Clades I and II were found (Table 1), with Clade I found in all sites but Clade II only in Mozambique and Zambia. A repeat of the single Clade II specimen from Kamuli in Uganda was performed and it was still assigned to Clade II. However, many more $A n$. funestus samples need to be examined, given that the TaqMan assay has been shown to have some limitations in its accuracy [37].

\section{Genetic diversity}

Levels of microsatellite polymorphism were moderate to high for all the twelve loci. One site from Malawi and two from Uganda had small sample sizes (less than 15 specimens, Table 1) but this did not affect the level of microsatellite polymorphism $(P>0.05)$ compared with previous studies. Overall, the mean observed heterozygosity $\left(\mathrm{H}_{\mathrm{o}}\right)$ values ranged from 0.26 to 0.42 and expected heterozygosity $\left(\mathrm{H}_{\mathrm{e}}\right)$ from 0.65 to 0.79 (Additional file 1: Table S1). These heterozygosity values were not significantly different among populations $(P=0.36)$. A summary of the mean variation of microsatellite loci from each country is presented in Table 3. Overall allelic richness averaged seven alleles per locus with a range of 2-19 (Table 2). Locus FUNQ had the lowest number of alleles $(n=2)$ and AFUB11 the greatest number of alleles $(n=19)$.

\section{Hardy-Weinberg equilibrium}

When samples were analyzed as a single population (i.e. pooled together), three loci (AFUB19, FUNQ and FUNF) of the twelve showed significant deviations from the Hardy-Weinberg equilibrium (HWE). This may have been due to significant heterozygote deficiency or due to the sub-structuring within the population. When these were removed no significant deviation was observed.

\section{Genetic differentiation and population structure}

Genetic divergence between the sampling groups estimated by $\mathrm{F}_{\mathrm{ST}}$ ranged from low to moderate. Values between $0.00-0.05$ indicate little divergence, $0.05-0.15$ moderate divergence, $0.15-0.25$ high divergence and over 0.25 a very high degree of divergence [30, 38, 39]. Genetic differentiation between all pairs of the sites and samples was estimated based on allele frequency differences at microsatellite level between the studied populations. The values of $\mathrm{F}_{\mathrm{ST}}$ between pairwise population comparisons for all loci varied from 0.006 to 0.396 across populations. These were significant within countries $(P<0.05)$ for Mozambique (Maciana and Matola), Uganda (between Kamuli and the other three localities) and Zambia (Nchelenge and Namwala) (Table 4). The 


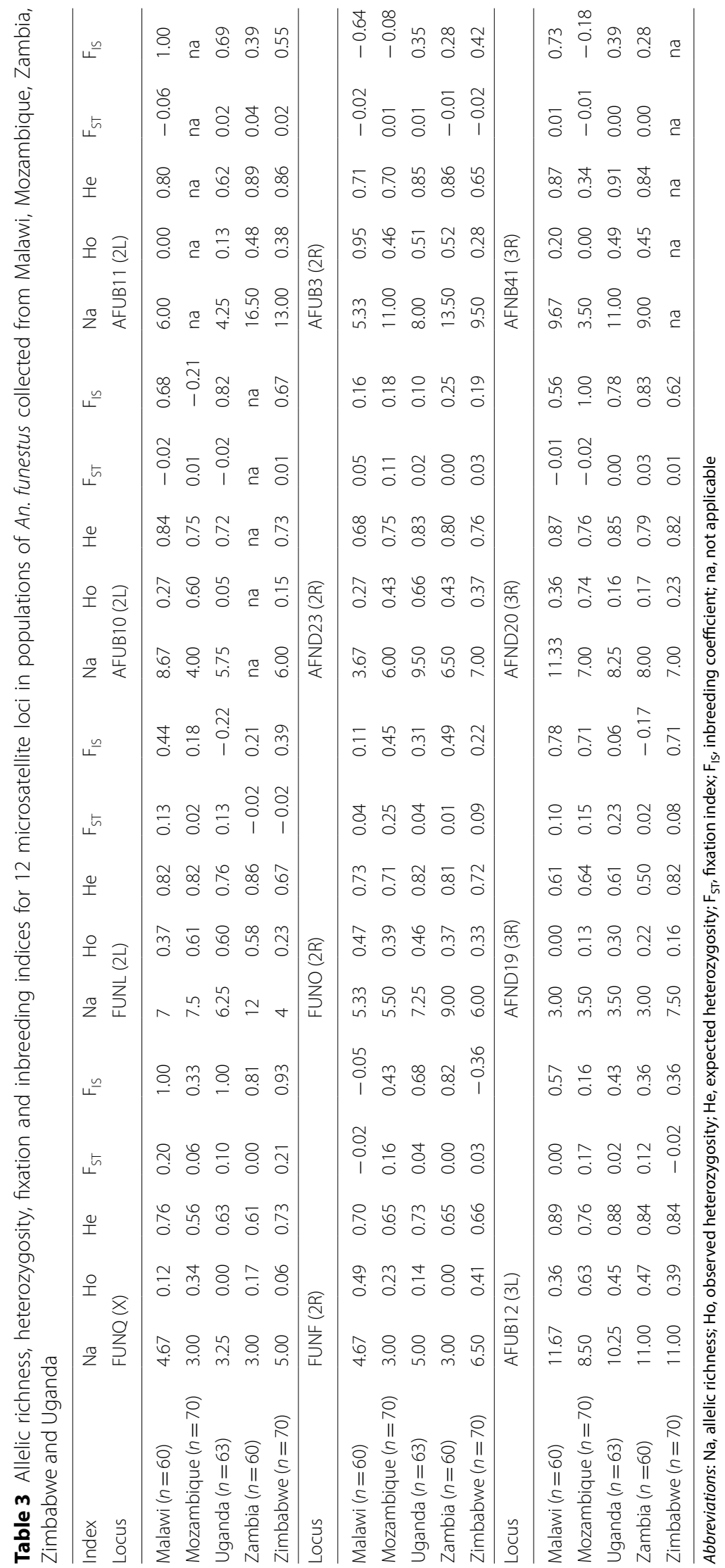


Table 4 Pairwise comparison of genetic diversity (FST) among the 13 geographical An. funestus populations sampled

\begin{tabular}{|c|c|c|c|c|c|c|c|c|c|c|c|c|c|}
\hline & Malawi & & & Mozamb & & Zambia & & Zimba & & Uganda & & & \\
\hline & Kar & Lik & Maj & Mac & Mat & Nche & Nam & Man & Hon & Lira & Agul & Apa & Kam \\
\hline Kar & 0.000 & & & & & & & & & & & & \\
\hline Lik & 0.044 & 0.000 & & & & & & & & & & & \\
\hline Maj & 0.054 & 0.029 & 0.000 & & & & & & & & & & \\
\hline Mac & -0.022 & 0.007 & 0.014 & 0.000 & & & & & & & & & \\
\hline Mat & -0.017 & -0.073 & 0.038 & $0.109^{*}$ & 0.000 & & & & & & & & \\
\hline Nche & -0.033 & 0.045 & 0.025 & 0.014 & 0.038 & 0.000 & & & & & & & \\
\hline Nam & 0.093 & 0.092 & 0.108 & 0.120 & 0.025 & $0.032^{*}$ & 0.000 & & & & & & \\
\hline Man & 0.034 & -0.027 & -0.040 & 0.029 & 0.025 & 0.093 & 0.108 & 0.000 & & & & & \\
\hline Hon & 0.092 & -0.034 & -0.027 & -0.019 & 0.040 & 0.009 & 0.012 & 0.396 & 0.000 & & & & \\
\hline Lira & 0.022 & 0.007 & 0.013 & 0.041 & 0.126 & 0.063 & 0.014 & 0.053 & 0.170 & 0.000 & & & \\
\hline Agul & 0.016 & 0.021 & 0.018 & 0.210 & 0.247 & 0.038 & 0.026 & 0.016 & 0.012 & 0.023 & 0.000 & & \\
\hline Apa & 0.034 & 0.052 & 0.127 & 0.019 & 0.018 & 0.041 & 0.013 & 0.035 & 0.198 & 0.029 & 0.026 & 0.000 & \\
\hline Kam & 0.112 & 0.191 & 0.135 & 0.891 & 0.198 & 0.135 & 0.298 & 0.144 & 0.112 & $0.054^{*}$ & $0.006^{*}$ & $0.070^{*}$ & 0.000 \\
\hline
\end{tabular}

*P $<0.05$

Abbreviations: Mal, Malawi; Kar, Karonga; Lik, Likoma; Maj, Majete; Moz, Mozambique; Mac, Maciana; Mat, Matola; Zam, Zambia; Nche, Nchelenge; Nam, Namwala; Zim, Zimbabwe; Man, Mangwanda; Hon, Honde; Uga, Uganda; Lir, Lira; Agul, Agule; Apa, Apac; Kam, Kamuli

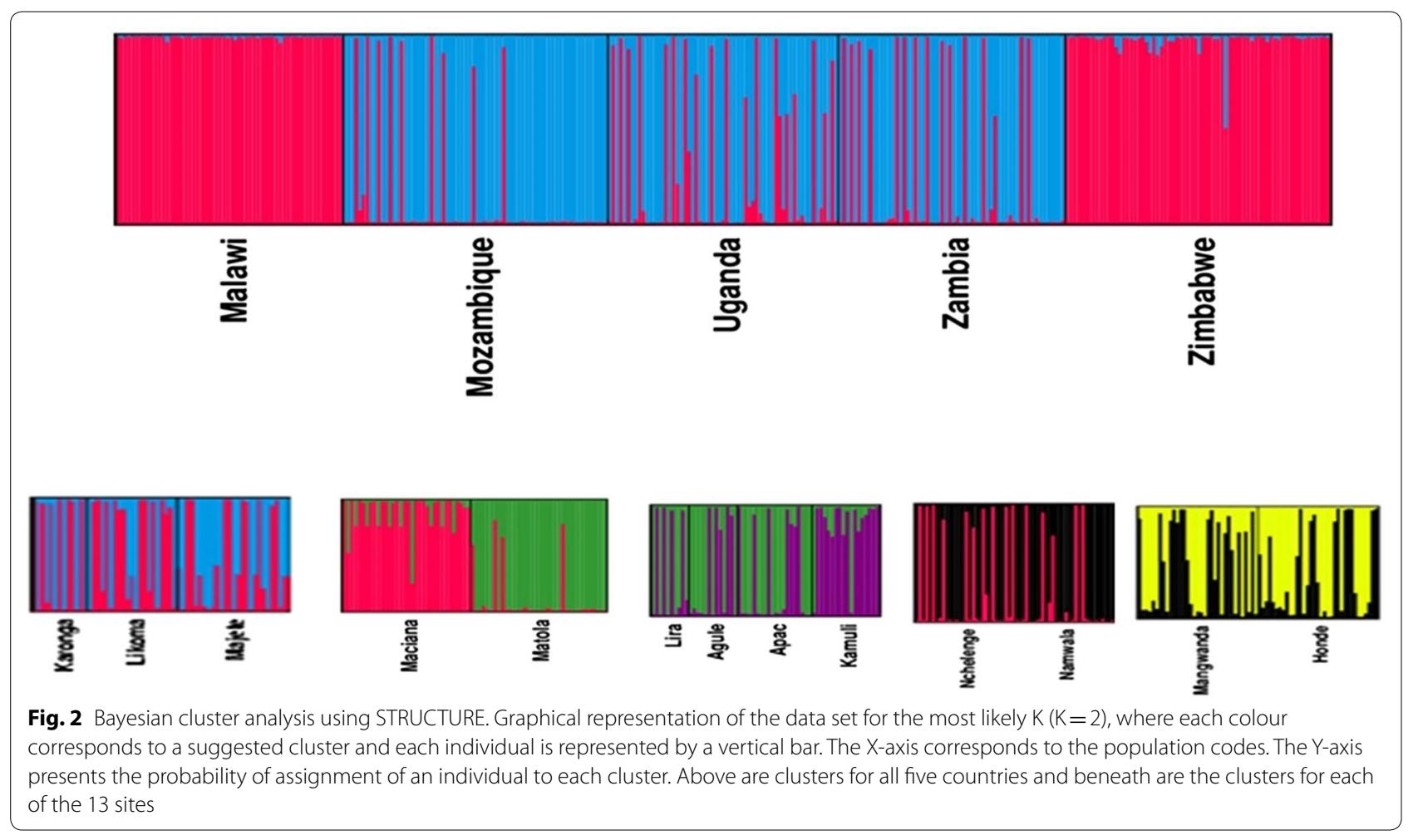

highest pairwise $F_{S T}$ estimates were obtained for the Malawi sites (Likoma and Majete) and the Zimbabwe sites (Honde and Mangwanda) but these were not significantly different $(P>0.05)$. Sites in Malawi varied between 0.029 (Likoma) to 0.054 (Karonga), 0.12 between Maciana and Matola, 0.013 between Mangwanda and Honde and the highest divergence was between all the sites in northern Uganda and Kamuli. Over all populations studied, the $\mathrm{F}_{\mathrm{ST}}$ estimate was 0.116 indicating that there was some genetic structure in the dataset $(P<0.05)$. This suggests that there are levels of genetic differentiation among populations within the selected countries. 
Table 5 Analysis of molecular variance (AMOVA) of twelve microsatellite loci in the An. funestus populations from Malawi, Mozambique, Uganda, Zambia and Zimbabwe

\begin{tabular}{lllc}
\hline Source of variation & Sum of squares & Variance components & $\begin{array}{c}\text { Percentage } \\
\text { variation }\end{array}$ \\
\hline Among groups & 123.335 & 0.008 & 0.214 \\
Among groups within populations & 121.684 & 0.429 & 11.074 \\
Among individuals within populations & 1701.694 & 1.947 & 50.247 \\
Within individuals & 478.500 & 1.491 & 38.466 \\
\hline
\end{tabular}

Note: Most of the variation is among individuals within the selected populations

STRUCTURE provided consistent results over 5 replicated runs tested for each $\mathrm{K}$. The probability of data Ln $\operatorname{Pr}(\mathrm{X} \mid \mathrm{K})$ increased from $\mathrm{K}=1$ to $\mathrm{K}=2$ until it reached a maximum value at $K=2$, after which values decreased gradually for all countries (Fig. 2). Thus, in agreement with the $\mathrm{F}_{\mathrm{ST}}$ results, the most likely number of genetic clusters in the dataset was two. However, when STRU CTURE was re-run with only 8 loci, three clusters were obtained for Malawi and Mozambique, and the rest of the countries retained the original two clusters (Additional file 2: Figure S1).

Additional insight into how variation was partitioned across the countries was shown by an analysis of molecular variance (AMOVA). The AMOVA of all twelve microsatellites confirmed the differentiation and structure analysis with the variation between individuals, within populations, and among populations, being $38 \%, 50.24 \%$ and $0.21 \%$ (Table 5), respectively. Variation among individuals within populations and among individuals explained $50 \%$ and $38 \%$ of the total variation, respectively. Almost all genetic diversity $(88 \%)$ was partitioned within populations, indicating small differences. Global $\mathrm{F}_{\mathrm{ST}}$ estimates revealed a slight but significant overall degree of genetic divergence $(P<0.05$ on 30,000 Markov chains) (Table 6). Only for Uganda were conditions suitable for AMOVA and much of the variation was recorded as among individuals within populations. This is in accordance with other studies that have found that most of the variation was with individuals among populations [12, 40-42].

\section{Isolation by distance and gene flow}

A Mantel test for Matrix correspondence called the isolation by distance (IBD) hypothesis was performed separately for each country using GenAlEx 6.501 to test for the occurrence of a positive correlation $(\mathrm{Rxy}>0)$ between the genetic matrix and the geographical distances. For Malawi, the villages of Karonga, Likoma and Majete showed an Rxy of 0.083, $P=0.007$; for Mozambique, Maciana and Matola villages, $\mathrm{Rxy}=0.257, P=0.07$; for Zambia, Nchelenge and Namwala, Rxy $=0.026, P=0.007$; for Zimbabwe, Mangwanda and Honde Rxy 0.071, $P=0.005$; and for Uganda, Kamuli, Apac, Agule and Lira, $\mathrm{Rxy}=0.15, P=0.023$. A low but significant correlation for Malawi, Zambia, Zimbabwe and Uganda was observed. No significant difference was observed for Mozambique $(P<0.05)$. The estimates of gene flow among An. funestus populations suggests that there is a range of gene flow between country level collections $\left(\mathrm{N}_{\mathrm{em}}\right.$ ranging from 0.03 to 41 ), with some populations more reproductively isolated than others with $\mathrm{N}_{\mathrm{em}}$ country averages of 6,2 , 8, 18 and 14, for Malawi, Mozambique, Zambia, Zimbabwe and Uganda, respectively (Table 7). The highest $\mathrm{N}_{\mathrm{em}}$ country average was in the Zimbabwe populations.

\section{Principal coordinates analysis}

The PCoA analysis found that the two most important principal coordinate axes accounted for less than $80 \%$ of the total variance in relatedness between genetic and geographical distance for An. funestus microsatellite loci, which would be the threshold required for statistical significance in PCoA (Fig. 3). The top two PCoA

Table 6 Global test of differentiation

\begin{tabular}{llllll}
\hline Country & Malawi & Mozambique & Uganda & Zambia & Zimbabwe \\
\hline Malawi & 0.000 & $0.000 \pm 0.000$ & $0.000 \pm 0.000$ & $0.000 \pm 0.000$ & $0.000 \pm 0.000$ \\
Mozambique & $0.116^{*}$ & 0.000 & $0.000 \pm 0.000$ & $0.000 \pm 0.000$ & $0.000 \pm 0.000$ \\
Uganda & $0.125^{*}$ & $0.135^{*}$ & 0.000 & $0.009 \pm 0.009$ & $0.000 \pm 0.000$ \\
Zambia & $0.141^{*}$ & $0.141^{*}$ & $0.028^{*}$ & 0.000 & $0.000 \pm 0.000$ \\
Zimbabwe & $0.094^{*}$ & $0.136^{*}$ & $0.116^{*}$ & $0.117^{*}$ & 0.000 \\
\hline
\end{tabular}

${ }^{*} P<0.05$ 
Table $7 \mathrm{~N}_{\mathrm{em}}$ comparisons for all the five countries

\begin{tabular}{|c|c|c|c|c|c|c|c|c|c|c|c|c|c|}
\hline & Malan & & & Mozam & & Zambi & & Zimba & & Uganc & & & \\
\hline & Kar & Lik & Maj & Mac & Mat & Nche & Nam & Man & Hon & Lira & Agul & Apa & Kam \\
\hline Kar & - & & & & & & & & & & & & \\
\hline Lik & 5.43 & - & & & & & & & & & & & \\
\hline Maj & 4.38 & 8.37 & - & & & & & & & & & & \\
\hline Mac & 11.36 & 35.46 & 2.1 & - & & & & & & & & & \\
\hline Mat & 14.45 & 3.17 & 6.32 & 2.04 & - & & & & & & & & \\
\hline Nche & 7.33 & 5.30 & 9.75 & 17.60 & 6.32 & - & & & & & & & \\
\hline Nam & 2.44 & 2.47 & 2.06 & 1.83 & 9.75 & 6.81 & - & & & & & & \\
\hline Man & 7.35 & 9.01 & 6.00 & 8.37 & 9.75 & 2.44 & 2.06 & - & & & & & \\
\hline Hon & 2.47 & 7.10 & 9.01 & 13.15 & 6.00 & 27.52 & 20.83 & 18.2 & - & & & & \\
\hline Lira & 11.36 & 35.46 & 18.98 & 5.85 & 1.73 & 3.72 & 17.60 & 4.47 & 1.22 & - & & & \\
\hline Agul & 17.60 & 11.65 & 13.64 & 0.94 & 0.76 & 6.33 & 9.34 & 15.38 & 20.58 & 10.86 & - & & \\
\hline Apa & 7.10 & 4.56 & 1.72 & 12.90 & 13.64 & 5.85 & 18.98 & 6.89 & 1.01 & 8.37 & 9.36 & - & \\
\hline Kam & 1.98 & 1.06 & 1.60 & 0.03 & 1.01 & 1.60 & 0.59 & 1.49 & 1.98 & 5.43 & 41.4 & 1.54 & - \\
\hline
\end{tabular}

Abbreviations: Mal; Malawi; Kar, Karonga; Lik, Likoma; Maj, Majete; Moz, Mozambique; Mac, Maciana; Mat, Matola; Zam, Zambia; Nche, Nchelenge; Nam, Namwala; Zim, Zimbabwe; Man, Mangwanda; Hon, Honde; Uga, Uganda; Lir, Lira; Agul, Agule; Apa, Apac; Kam, Kamuli

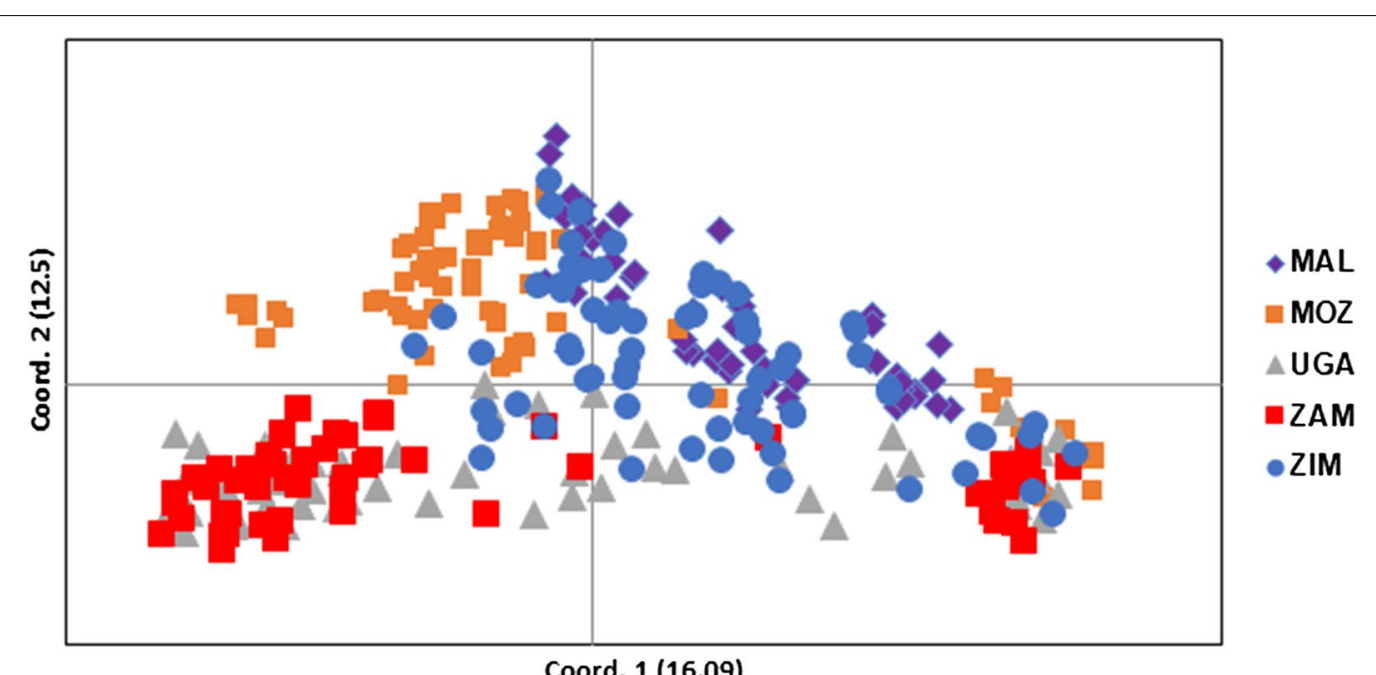

Fig. 3 Principal coordinates analysis (PCOA) generated from 12 microsatellites among five An. funestus populations from Uganda and southern African countries. Abbreviations: MAL, Malawi; MOZ, Mozambique; UGA, Uganda; ZAM, Zambia; ZIM, Zimbabwe

components explained $16.1 \%$ and $12.5 \%$ of the total variance and grouped the individuals into two main clusters (Fig. 3). Groupings were between Malawi and Mozambique, and Uganda and Zambia. Zimbabwe samples uniquely mixed with all the other populations.

\section{Discussion}

Genetic methods of assessing An. funestus population structure and differentiation were employed to provide information on within and between population differentiation, diversity and gene flow. Understanding these characteristics allows for better tailoring of vector control methods. Molecular data revealed overall high genetic variability among An. funestus populations from eastern and southern Africa, highlighting an important level of allelic richness and gene diversity.

Low to moderate differentiation of the 13 An. funestus populations studied was shown at the nuclear DNA level with the 12 microsatellites genotyping as polymorphic across sites. This is consistent with low to moderate levels of genetic differentiation found in individuals among An. funestus populations in east, west 
and southern Africa [12, 18, 19, 39-42] and in other Anopheles species [19, 43-45]. The low to moderate levels of genetic differentiation may also be the result of barriers to gene flow between the populations. In our case, genetic differentiation among the sampled $A n$. funestus populations had a weak yet significant correlation with geographical distance and therefore might be affected by other factors that need investigation. Our findings confirm those of Ayala et al. [40], Michel et al. [12] and Barnes et al. [15], who found An. funestus to be structured following a similar pattern of isolation by distance. The differentiation deviations could be a result of inbreeding as observed in the high $\mathrm{F}_{\mathrm{IS}}$ values for some populations. In addition, these values could also be attributed to the presence of the Wahlund effect (reduction of heterozygosity caused by subpopulation structure) or the spatial pooling of individuals originating from different houses or focal points [46]. Changes have taken place over the studied populations and collections were done at different times and over different years and this could be influencing the HWE of $A n$. funestus populations $[47,48]$. HWE states that the genes and genotypes will remain constant in the absence of migration, genetic drift and inbreeding from generation to generation $[30,48]$. The changes in this instance could also have been caused by epistatic natural selection and random genetic drift. These features can affect the flow of genes conditioning vector competence and insecticide resistance. However, other factors such as microclimate, increasing urbanization and global warming may play a part that needs to be investigated.

The rate of gene flow over time is considered suitable for estimating exchange of genes between populations [38]. $\mathrm{N}_{e m}$ values of gene flow for An. funestus populations have been reported to vary from 17 to 483 [12, 18, 39]. The recorded values of $\mathrm{N}_{e m}$ for An. funestus in this study were much lower [3-40], probably as a result of the geographical distances between the populations which ranged from $140 \mathrm{~km}$ between Maciana and Matola in Mozambique, to $3000 \mathrm{~km}$ between the most southern site of Matola and the most northern site of Lira in Uganda. Furthermore, samples were collected at different time points spanning 10 years and in different seasons. Thus geographical distances that separate the studied populations may not be the only barriers to limit gene flow among them, but other environmental factors may also play a role. Analysis of molecular variance indicated that most of the genetic variation $(88 \%)$ was maintained within the populations rather than between them. These results confirm findings of Barnes et al. [15], Michel et al.
[12] and Ogola et al. [18] from countries in east, west and southern Africa.

A study on upregulation of insecticide resistance metabolic enzyme genes provided evidence of population structuring between northern and southern sites in Malawi [16]. The Mantel test used here for correlation of genetic variation with geographical distance (isolation by distance hypothesis) showed positive correlation between sites in Malawi $\left(R_{x y}=0.083, P=0.007\right)$, not indicating environmental or other barriers to gene flow. Only the two sites in Mozambique (Matola and Maciana, $140 \mathrm{~km}$ apart) gave negative results for isolation by distance. Genetic/geographical distance correlations are variable with previous studies showing these to be weak but significant $[12,22]$, weak and non-significant [18], or nonexistent [19].

Using genetic structure analysis, the populations studied here were clustered into two groups, Malawi/Zimbabwe versus Uganda/Zambia/Mozambique. These groups do not coincide with the mitochondrial Clades I and II of Choi et al. [21], both of which were shown to occur in Mozambique and Zambia in the present study. A recent study by Jones et al. [37] based on the full mitogenomes of An. funestus from Zambia, the Democratic Republic of Congo and Tanzania, showed that there were two strong maternal lineages in Zambia and Tanzania. Whether the PCoA results illustrated in Fig. 3 here, showing two distinct clusters in the Zambian sample reflect the mitogenome clusters, remains to be confirmed. The TaqMan assay [21] was not always accurate in identifying the clades [37] and this might also impact on the results shown in our study.

\section{Conclusions}

Two genetically distinct clusters were revealed in $A n$. funestus with populations from Mozambique, Uganda and Zambia forming one group and Malawi and Zimbabwe the second group. However, almost all genetic diversity (88\%) was partitioned within populations, indicating small differences, except for the PCoA of the Zambian samples which were clearly divergent. The variable effective population sizes, climate and different collection time points, may be some of the factors affecting the differentiation. Future research should investigate changes in mosquito populations over time, especially as insecticide use and their coverage evolve, new interventions are rolled out, and climate/land use changes. 


\section{Supplementary information}

Supplementary information accompanies this paper at https://doi. org/10.1186/s13071-020-3962-1.

Additional file 1: Table S1. Population comparisons, HW proportions and independence of loci (significant values recorded in bold).

Additional file 2: Figure S1. Structure clusters by population in each of the countries, Malawi, Mozambique, Uganda, Zambia and Zimbabwe with eight microsatellites. The X-axis corresponds to the population codes. The Y-axis presents the probability of assignment of a population to each cluster.

\section{Abbreviations}

PCR: Polymerase chain reaction; AMOVA: Analysis of molecular variance; FSTAT : Fisher's exact test; IBD: Isolation by distance; MCMC: Markov Chain Monte Carlo; PP: Primers present in analysis column; IAC: Indoor aspiration collection; HLC: Human landing collection; s.s.: Sensu stricto.

\section{Acknowledgements}

A number of people provided field assistance, mosquitoes and information used in the study. Kwang Shik Choi, Lizette Koekemoer, Jean Mollett and Frederic Tripet are thanked for comments on the manuscript.

\section{Authors' contributions}

MK developed the study concept and design, and was responsible for data analysis and wrote the first draft of the manuscript. JW and MC provided conceptual input and guided the data interpretation. MM, JS and DN assisted with samples from the southern and Central Africa ICEMR project and with data interpretation. All authors reviewed the manuscript and contributed to the final submission. All authors read and approved the final manuscript.

\section{Funding}

MAK was supported by an NRF-TWAS post-doctoral fellowship at the University of Witwatersrand, Johannesburg, South Africa and a DST/NRF SARChl grant to MC. Samples from Zambia and Zimbabwe were obtained from the Southern and Central African International Center of Excellence for Malaria Research (ICEMR) Grant to the John Hopkins School of Public Health (Grant No. U19 Al1089680). South African Agency for Science and Technology Advancement (Grant No. F14/25)

\section{Availability of data and materials}

All data generated or analysed during this study are included in this published article and its additional files.

\section{Ethics approval and consent to participate}

Mosquito collections were conducted following verbal consent from Local Council personnel and household owners. Ethical review committees in Malawi and Mozambique approved the protocol for mosquito collection. In Zambia and Zimbabwe ethical review committees at Johns Hopkins School of Public Health, USA (IRB: 00003467) and the Tropical Diseases Research Centre, Ndola, Zambia (TDRC/ERC/2010/14/11) or National Health Research Institute, Harare, Zimbabwe approved the protocol. For Uganda, the protocol was approved by the Wits Research Institute (W-CJ-150911-1) and Uganda National Council for Science and Technology UNCST/NS 330. This manuscript was approved for publication by the National Health Research Authority of Zambia.

\section{Consent for publication}

Not applicable.

\section{Competing interests}

The authors declare that they have no competing interests.

\section{Author details}

${ }^{1}$ Wits Research Institute for Malaria, School of Pathology, Faculty of Health Sciences, University of the Witwatersrand, Johannesburg, South Africa.

${ }^{2}$ Inqaba Biotechnical Industries, PO Box 14356, Hatfield, 0028 Pretoria, South Africa. ${ }^{3}$ Macha Research Trust, Choma District, Zambia. ${ }^{4}$ Southern and Central
Africa International Centers of Excellence in Malaria Research, Department of Molecular Microbiology and Immunology, John Hopkins Malaria Research Institute, Johns Hopkins Bloomberg School of Public Health, Baltimore, USA. ${ }^{5}$ Center for Emerging Zoonotic and Parasitic Diseases, National Institute for Communicable Diseases, Johannesburg, South Africa.

Received: 18 November 2019 Accepted: 11 February 2020

Published online: 18 February 2020

\section{References}

1. Gillies MT, De Meillon B. The Anophelinae of Africa South of the Sahara. Publ S Afr Inst Med Res. 1968;54:1-343.

2. Gillies MT, Coetzee M. A supplement to the Anophelinae of Africa South of the Sahara. Publ S Afr Inst Med Res. 1987:55:1-141.

3. Sinka ME, Bangs MJ, Manguin S, Coetzee M, Mbogo CM, Hemingway J, et al. The dominant Anopheles vectors of human malaria in Africa, Europe and the Middle East: occurrence data, distribution maps and bionomic précis. Parasites Vectors. 2010:3:117.

4. Coetzee M, Fontenille D. Advances in the study of Anopheles funestus, a major vector of malaria in Africa. Insect Biochem Mol Biol. 2004;34:599-605.

5. Coetzee M, Koekemoer LL. Molecular systematics and insecticide resistance in the major African malaria vector, Anopheles funestus. Ann Rev Entomol. 2013;58:393-412.

6. Choi KS, Christian R, Nardini L, Wood OR, Agubuzo E, Muleba M, et al. Insecticide resistance and role in malaria transmission of Anopheles funestus populations from Zambia and Zimbabwe. Parasites Vectors. 2014;7:464

7. Hargreaves K, Koekemoer LL, Brooke BD, Hunt RH, Mthembu J, Coetzee M. Anopheles funestus is resistant to pyrethroid insecticides in South Africa. Med Vet Entomol. 2000;14:181-9.

8. Mugenzi LMJ, Menze BD, Tchouakui M, Wondji MJ, Irving H, Tchoupo $M$, et al. Cis-regulatory CYP6P9b P450 variants associated with loss of insecticide-treated bed net efficacy against Anopheles funestus. Nat Commun. 2019;10:4652.

9. Riveron JM, Huijben S, Tchapga W, Tchouakui M, Wondji MJ, Tchoupo M, et al. Escalation of pyrethroid resistance in the malaria vector Anopheles funestus induces a loss of efficacy of piperonyl butoxide-based insecticide-treated nets in Mozambique. J Infect Dis. 2019;220:467-75.

10. WHO. World malaria report 2018. Geneva: World Health Organization; 2018. https://www.who.int/malaria/publications/world-malaria-repor t-2018/en. Accessed 28 Jan 2019.

11. Sinka ME, Golding N, Massey NC, Wiebe A, Huang Z, Hay SI, Moyes CL. Modelling the relative abundance of the primary African vectors of malaria before and after the implementation of indoor, insecticidebased vector control. Malar J. 2016;15:142.

12. Michel AP, Ingrasci MJ, Schemerhorn BJ, Kern M, Le Goff G, Coetzee M, et al. Rangewide population genetic structure of the African malaria vector Anopheles funestus. Mol Ecol. 2005;14:4235-48.

13. Morgan JC, Irving H, Okedi LM, Steven A, Wondji CS. Pyrethroid resist ance in an Anopheles funestus population from Uganda. PLOS ONE. 2010;5:e11872

14. Mulamba C, Riveron JM, Ibrahim SS, Irving H, Barnes KG, Mukwaya LG, et al. Widespread pyrethroid and DDT resistance in the major malaria vector Anopheles funestus in East Africa is driven by metabolic resistance mechanisms. PLoS ONE. 2014;9:e110058.

15. Barnes KG, Weedall GD, Ndula M, Irving H, Mzihalowa T, Hemingway J, Wondji CS. Genomic footprints of selective sweeps from metabolic resistance to pyrethroids in African malaria vectors are driven by scale up of insecticide-based vector control. PLoS Genet. 2017;13:e1006539.

16. Barnes KG, Irving H, Chiumia M, Mzilahowa T, Coleman M, Hemingway J. Wondji CS. Restriction to gene flow is associated with changes in the molecular basis of pyrethroid resistance in the malaria vector Anopheles funestus. Proc Nat Acad Sci USA. 2017:114:286-91.

17. Choi KS, Koekemoer LL, Coetzee M. Population genetic structure of the major malaria vector Anopheles funestus s.s. and allied species in southern Africa. Parasites Vectors. 2012;5:283. 
18. Ogola EO, Odero JO, Mwangangi JM, Masiga DK, Tchouassi DP. Population genetics of Anopheles funestus, the African malaria vector, Kenya. Parasites Vectors. 2019;12:15.

19. Gélin P, Magalon H, Drakeley C, Maxwell C, Magesa S, Takken W, Boëte C. The fine-scale genetic structure of the malaria vectors Anopheles funestus and Anopheles gambiae (Diptera: Culicidae) in the northeastern part of Tanzania. Int J Trop Insect Sci. 2016;36:161-70.

20. Koekemoer LL, Kamau L, Hunt RH, Coetzee M. A cocktail polymerase chain reaction assay to identify members of the Anopheles funestus (Diptera: Culicidae) group. Am J Trop Med Hyg. 2002;66:804-11.

21. Choi KS, Coetzee M, Koekemoer LL. Detection of clade types (clades I and II) within Anopheles funestus sensu stricto by the hydrolysis probe analysis (TaqMan assay). Parasites Vectors. 2013;6:173.

22. Cohuet A, Simard F, Berthomieu A, Raymond M, Fontenille D, Weill M. Isolation and characterization of microsatellite DNA markers in the malaria vector Anopheles funestus. Mol Ecol Notes. 2002;2:498-500.

23. Sharakov IV, Braginets $\mathrm{O}, \mathrm{Mbogo} C N$, Yan G. Isolation and characterization of trinucleotide microsatellites in the African malaria mosquito Anopheles funestus. Mol Ecol Notes. 2001;1:289-92.

24. Sharakov I, Braginets O, Grushko O, Cohuet A, Guebeogo M, Boccolini $D$, et al. A microsatellite map of the African human malaria vector Anopheles funestus. J Hered. 2004;95:29-34.

25. Schermerhorn BJ, Greeman S, Banks M, Vulule J, Sagnon N'F, Costantini C, Besansky NJ. Dinucleotide microsatellite markers from Anopheles funestus. Mol Ecol Notes. 2003;3:505-7.

26. Excoffier $\mathrm{L}$, Lischer HEL. Arlequin suite version 3.5: a new series of programs to perform population genetics analyses under Linux and Windows. Mol Ecol Resour. 2010;10:564-7.

27. Goudet J. FSTAT, Version 2.9.3. A program to estimate and test gene diversities and fixation indices. 2001. www.unil.ch/izea/softwares/fstat html. Accessed 17 Jan 2017.

28. Weir BS, Cockerham CC. Estimating F-statistics for the analysis of population structure. Evolution. 1984;38:1358-70.

29. Excoffier L, Smouse PE, Quattro JM. Analysis of molecular variance inferred from metric distances among DNA haplotypes: application to human mitochondrial DNA restriction data. Genetics. 1992;131:479-91.

30. Pritchard JK, Stephens M, Donnelly P. Inference of population structure using multilocus genotype data. Genetics. 2000;155:945-59.

31. Earl DA, von Holdt BM. STRUCTURE HARVESTER: a website and program for visualizing STRUCTURE output and implementing the Evanno method. Conserv Genet Resour. 2012;4:359-61.

32. Jakobsson M, Rosenberg NA. CLUMPP: a cluster matching and permutation program for dealing with label switching and multimodality in analysis of population structure. Bioinformatics. 2007;23:1801-6.

33. Rosenberg NA. Distruct: a program for the graphical display of population structure. Mol Ecol Notes. 2004;4:137-8.

34. Slatkin M. A measure of population subdivision based on microsatellite allele frequencies. Genetics. 1995;139:457-62.
35. Peakall R, Smouse PE. GENALEX 6: genetic analysis in Excel. Population genetic software for teaching and research. Mol Ecol Notes. 2006:6:288-95.

36. Peakall R, Smouse PE. GenAlEx 6.5: genetic analysis in Excel. Population genetic software for teaching and research-an update. Bioinformatics. 2012;28:2537-9.

37. Jones CM, Lee Y, Kitchen A, Collier T, Pringle JC, Muleba M, et al. Complete Anopheles funestus mitogenomes reveal an ancient history of mitochondrial lineages and their distribution in southern and central Africa. Sci Rep. 2018;8:9054.

38. Slatkin S. Rare alleles as indicators of gene flow. Evolution. 1985;39:53-65

39. Braginets OP, Minakawa N, Mbogo CM, Yan G. Population genetic structure of the African malaria mosquito Anopheles funestus in Kenya. Am J Trop Med Hyg. 2003;69:303-8.

40. Ayala D, Le Goff G, Robert V, Takken WJ. Population structure of the malaria vector Anopheles funestus (Diptera: Culicidae) in Madagascar and Comoros. Acta Trop. 2006;97:292-300.

41. Samb B, Dia I, Konate L, Ayala D, Fontenille D, Cohuet A. Population genetic structure of the malaria vector Anopheles funestus, in a recently re-colonized area of the Senegal River basin and human-induced environmental changes. Parasites Vectors. 2012;5:188.

42. Michel AP, Grushko O, Wamdaogo M, Guelbeogo WM, Lobo NF, Sagnon $\mathrm{N}$, et al. Divergence with gene flow in Anopheles funestus from the Sudan savanna of Burkina Faso, West Africa. Genetics. 2006;173:1389-95.

43. Lehmann T, Licht M, Elissa N, Maega BT, Chimumbwa JM, Watsenga FT, et al. Population structure of Anopheles gambiae in Africa. J Hered. 2003:94:133-47.

44. Lehmann T, Besansky NJ, Hawley WA, Fahey TG, Kamau L, Collins FH. Microgeographic structure of Anopheles gambiae in western Kenya based on mtDNA and microsatellite loci. Mol Ecol. 1997;6:243-53.

45. Antonio-Nkondjio C, Ndo C, Kengne P, Mukwaya L, Awono-Ambene P, Fontenille D, Simard F. Population structure of the malaria vector Anopheles moucheti in the equatorial forest region of Africa. Malar J. 2008;7:120.

46. Carja O, Liberman U, Feldman MW. Evolution in changing environments: modifiers of mutation, recombination and migration. Proc Nat Acad Sci. 2014;11:17935-40.

47. Ma L, Zhang D, Ji YJ. Statistical measures of genetic differentiation of populations: rationales, history and current states. Curr Zool. 2015;61:886-96.

48. Bacaer N. The Hardy-Weinberg law (1908). In: Bacaer N, editor. A short history of mathematical population dynamics. London: Springer; 2011. p. 59-63.

\section{Publisher's Note}

Springer Nature remains neutral with regard to jurisdictional claims in published maps and institutional affiliations.
Ready to submit your research? Choose BMC and benefit from:

- fast, convenient online submission

- thorough peer review by experienced researchers in your field

- rapid publication on acceptance

- support for research data, including large and complex data types

- gold Open Access which fosters wider collaboration and increased citations

- maximum visibility for your research: over 100M website views per year

At BMC, research is always in progress.

Learn more biomedcentral.com/submissions 